\title{
Are meteorological factors enhancing COVID-19 transmission in Bangladesh? Novel findings from a compound Poisson generalized linear modeling approach
}

\author{
Abu Reza Md. Towfiqul Islam ${ }^{1}$ (D) $\cdot$ Md. Hasanuzzaman ${ }^{1} \cdot$ Mashura Shammi $^{2} \cdot$ Roquia Salam $^{1} \cdot$ Md. Bodrud-Doza $^{3}$. \\ Md. Mostafizur Rahman ${ }^{2} \cdot$ Md. Abdul Mannan ${ }^{4} \cdot$ Saleemul Huq ${ }^{5}$
}

Received: 28 May 2020 / Accepted: 15 October 2020 / Published online: 28 October 2020

(C) Springer-Verlag GmbH Germany, part of Springer Nature 2020

\begin{abstract}
Novel coronavirus (SARS-CoV-2) causing COVID-19 disease has arisen to be a pandemic. Since there is a close association between other viral infection cases by epidemics and environmental factors, this study intends to unveil meteorological effects on the outbreak of COVID-19 across eight divisions of Bangladesh from March to April 2020. A compound Poisson generalized linear modeling (CPGLM), along with a Monte-Carlo method and random forest (RF) model, was employed to explore how meteorological factors affecting the COVID-19 transmission in Bangladesh. Results showed that subtropical climate (mean temperature about $26.6{ }^{\circ} \mathrm{C}$, mean relative humidity (MRH) $64 \%$, and rainfall approximately $3 \mathrm{~mm}$ ) enhanced COVD-19 onset. The CPGLM model revealed that every $1 \mathrm{~mm}$ increase in rainfall elevated by $30.99 \%$ (95\% CI 77.18\%, - 15.20\%) COVID-19 cases, while an increase of $1{ }^{\circ} \mathrm{C}$ of diurnal temperature (TDN) declined the confirmed cases by $-14.2 \%(95 \%$ CI 9.73\%, $38.13 \%$ ) on the lag 1 and lag 2, respectively. In addition, NRH and MRH had the highest increase $(17.98 \%$ (95\% CI $22.5 \%$, $13.42 \%$ ) and $19.92 \%$ (95\% CI: $25.71 \%, 14.13 \%)$ ) of COVID-19 cased in lag 4. The results of the RF model indicated that TDN and AH (absolute humidity) influence the COVID-19 cases most. In the Dhaka division, MRH is the most vital meteorological factor that affects COVID-19 deaths. This study indicates the humidity and rainfall are crucial factors affecting the COVID-19 case, which is contrary to many previous studies in other countries. These outcomes can have policy formulation for the suppression of the COVID-19 outbreak in Bangladesh.
\end{abstract}

Keywords Bangladesh · COVID-19 · Compound Poisson generalized linear modeling (CPGLM) · Meteorological factors . Time-series analysis $\cdot$ Random forest $(\mathrm{RF})$

Responsible Editor: Gerhard Lammel

Abu Reza Md. Towfiqul Islam

towfiq_dm@brur.ac.bd

Md. Mostafizur Rahman

rahmanmm@juniv.edu

1 Department of Disaster Management, Begum Rokeya University, Rangpur 5400, Bangladesh

2 Department of Environmental Sciences, Jahangirnagar University, Dhaka 1342, Bangladesh

3 Climate Change Programme, BRAC, Dhaka, Bangladesh

4 Bangladesh Meteorological Department, Meteorological Complex Agargaon, Dhaka 1207, Bangladesh

5 ICCCAD, Independent University Bangladesh, Dhaka, Bangladesh

\section{Introduction}

Novel coronavirus (SARS-CoV-2) causing COVID-19 disease has arisen to be a pandemic and a dangerous component in strategic planning, critical policymaking, and time-worthy decisions in public health sectors worldwide. One of the significant challenges fighting against the COVID-19 virus was to understand the infective agent and its environmental behavior effectively. Climatological and atmospheric factors are the crucial considerations that might have influenced the tendencies of respiratory infectious diseases leading to epidemics (Ma et al. 2020; Wu et al. 2020).

However, the consequence of meteorological variables on COVID-19 remains debatable (Wu et al. 2020). For illustration, countries in temperate regions, epidemic peak timing, and intensity precision exceed $50 \%$ at 4 and 2 weeks before the forecasted epidemic peak, respectively, whereas the 
tropics and subtropics, epidemic forecasts are significantly less accurate for both peak timing and intensity (Kramer and Shaman 2019). Seasonally and spatially, the surges of influenza rise during the monsoon season in tropical climates, while during the dry and cold months of winter in temperate climates (Peci et al. 2019).

Low humidity and temperature enhance many types of flu virus transmission; its impact on mortality remains unclear (Kudo et al. 2019). A study on influenza viruses revealed that humidity was found to be a controlling factor. For example, in temperate areas of the world, the seasonality of influenza virus attack along with the survival of the virus is strongly related to the decline in humidity (Barreca and Shimshack 2012; Kudo et al. 2019).

A recent study reported that absolute humidity $(\mathrm{AH})$ is more significant than relative humidity $(\mathrm{RH})$ in regulating observed climate patterns (Marr et al. 2019). AH was a critical factor of observed influenza mortality, even after governing for temperature. Temperature modestly affected influenza mortality as well, although outcomes were less robust (Barreca and Shimshack 2012). The blending of temperature and $\mathrm{RH}$ is likewise acceptable as $\mathrm{AH}$ as a predictor, as upper levels of $\mathrm{AH}$ are only potential at elevated temperatures. At elevated temperatures, it is established that virus decline is swifter. In climatological data, outside $\mathrm{AH}$ substitutes for inside $\mathrm{RH}$ in temperate climate regions during the winter period (Marr et al. 2019). Furthermore, recently, the influenza epidemic might be associated with environmental air pollution and low temperature, and the outcome is an excess of mortality in Milan, Italy (Murtas and Russo 2019). Likewise, in temperate regions, the risk of influenza frequency was significantly heightened with low daily temperatures of $0-5{ }^{\circ} \mathrm{C}$ and low $(30-40 \%)$ or high $(70 \%) \mathrm{RH}$. A strong correlation between diurnal temperature and influenza incidence was found in South Korea (Park et al. 2020). From the Chinese study, it shows that both low AH and high $\mathrm{AH}$ are the reasons for other viral diseases such as pneumonia and influenza-related deaths among the elderly (Qi et al. 2020a).

Studies related to COVID-19 deaths and the relationship among meteorological and environmental factors are increasing, and at the same time, are crucial. Several cited works have been found concerning COVID-19 infection, mortality, and environmental factors. For instance, Wu et al. (2020) stated that the temperature and RH were both negatively associated with daily new cases and mortality. A $1{ }^{\circ} \mathrm{C}$ increase in temperature and a $1 \%$ increase in $\mathrm{RH}$ is related to $3.08 \%$ death rate reduction and $0.85 \%$ reduction of daily new cases of COVID-19 infection (Wu et al. 2020). Qi et al. (2020b) used the generalized additive model (GAM) to compute the province-specific relations among climatological factors and daily cases of COVID-19 in China. The study found that temperature and humidity presented negative associations with COVID-19, while a significant association between temperature and humidity existed. Temperate countries and regions with low humidity should be taken more considerate (Qi et al. 2020b). Ma et al. (2020) established a daily number of COVID-19 death with meteorological variables and air pollutant datasets in Wuhan, China, which was the starting point of the global pandemic. Another study conducted by Zhu et al. (2020) from 122 cities across China, established the epidemiological and experimental research on ambient temperature and COVID-19 infectious disease. Surrounding temperature is an essential factor affecting the transmission and survival of coronavirus (Zhu and Xie 2020). The mechanisms by which meteorological factors increase the rates of COVID-19 confirmed cases are still overlooked. Based on the available literature, it can be said that the concrete conclusion is yet to be drawn on the potential role of meteorological factors on COVID-19 worldwide. Therefore, it warrants more research on this topic in different regions of the world, including Bangladesh.

Bangladesh is a subtropical country of high population density that ranks 10 th in the world and a climatevulnerable country in the world (Bodrud-Doza et al. 2020; Shammi et al. 2020a). The first COVID-19 infection case was reported in Bangladesh on March 08, 2020 (IEDCR 2020; Shammi et al. 2020b). From then on September 01, 2020, the confirmed cases of infection and deaths are increasing exponentially (Fig. 1). However, we do not know the potential impacts of meteorological factors on the disease transmission and mortality in this country. Thus, the objectives of the current study were to investigate the effects of meteorological factors on COVID-19 confirmed cases and deaths in Bangladesh using compound Poisson generalized linear modeling (CPGLM), a unique approach across the eight divisions of Bangladesh along with the Monte-Carlo method and random forest (RF) model. The findings will add some unique insights into the possible correlations between the COVID-19 and meteorological factors. The uniqueness of the study is the first report from Bangladesh on the potential relationships between meteorological factors and COVID-19 confirmed cases.

\section{Data and methods}

\section{Study area}

Bangladesh is a low-lying riverine deltaic country that is positioned in South Asia (Islam et al. 2020a). Most of the land surface (about $80 \%$ ) is a floodplain, except for some parts in the northeastern and southeastern portions (Hills, hillocks). Bangladesh experiences a subtropical monsoon humid climate with distinct spatial variation (Islam et al. 2020b). Three main 
(a) COVID-19 cases in Bangladesh (As of 01 Sep 2020)
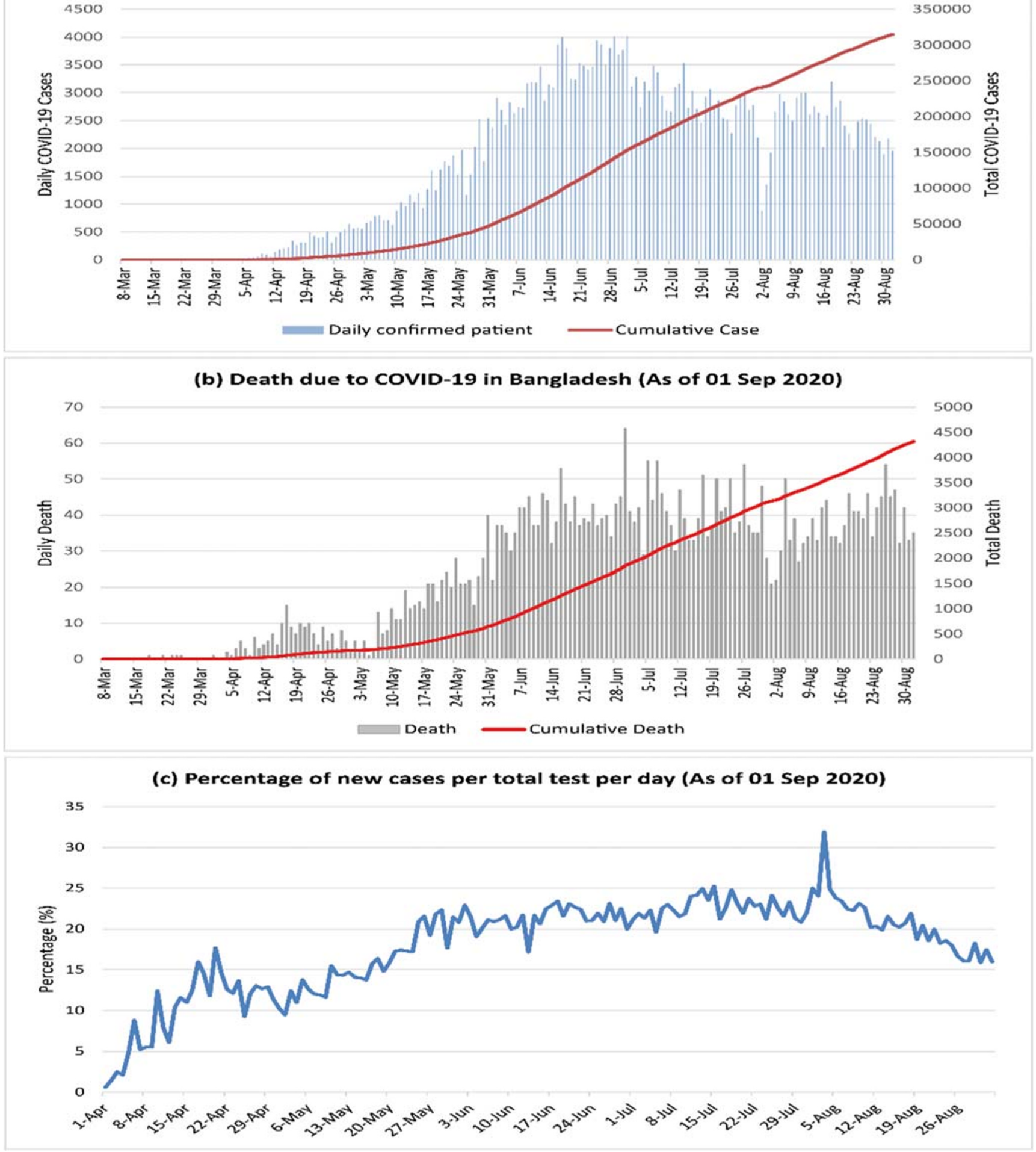

Fig. 1 The confirmed cases of the COVID-19 in Bangladesh until August 31, 2020

seasons prevail in this country that are the pre-monsoon, monsoon, and post-monsoon. The monsoon is a crucial driver of climatic variability in Bangladesh (Rahman and Islam 2019). Most of the precipitation (more than 50\%) occurred in this season. The average maximum, minimum temperatures, and relative humidity over the nation are $29.94{ }^{\circ} \mathrm{C}, 21.39{ }^{\circ} \mathrm{C}$, and $80 \%$, respectively. The spatial distribution of the number of COVID-19 cases (at district level) up to September 01, 2020 where there are now more than 250,000 COVID-19 cases in Bangladesh (Fig. 2). 


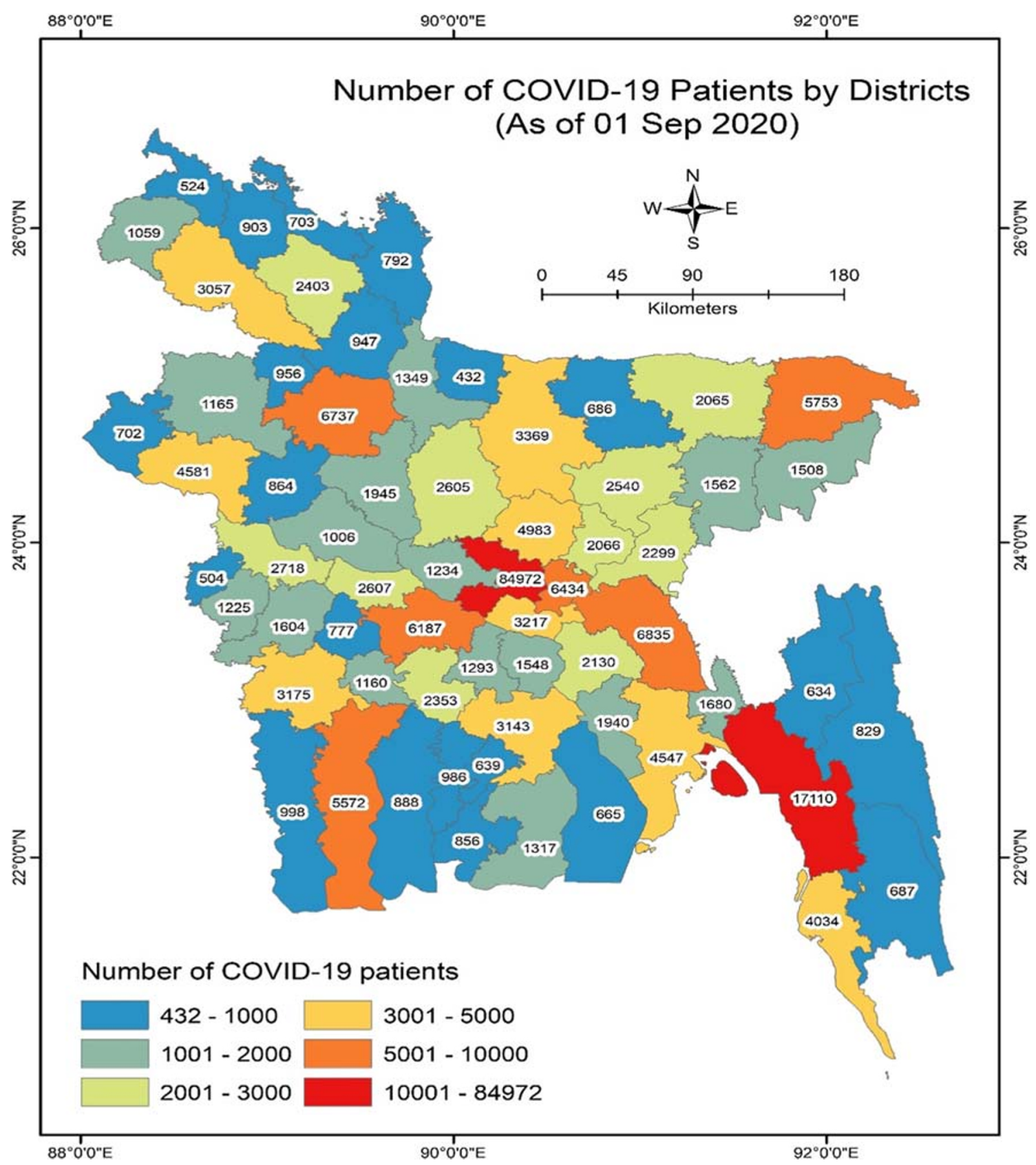

Fig. 2 Map showing the spatial distribution of number of the COVID-19 cases in Bangladesh

\section{Data sources}

Bangladesh Meteorological Department (BMD) has 43 weather stations across the country. The daily minimum temperature $\left(T_{\min }\right)\left({ }^{\circ} \mathrm{C}\right)$, maximum temperature $\left(T_{\max }\right)\left({ }^{\circ} \mathrm{C}\right)$, day relative humidity (DRH) $(\%)$, night relative humidity $(\mathrm{NRH})$ $(\%)$, and rainfall $(\mathrm{mm})$ datasets of 43 stations from March 8 to April 30, 2020 were collected from BMD (Islam et al. 2019, 2020a). Diurnal temperature (TDN) $\left({ }^{\circ} \mathrm{C}\right)$ and mean temperature (MT) were calculated from $T_{\min }$ to $T_{\max }$. Mean relative humidity (\%) (MRH) was also derived from day and night relative humidity $(\%)$. There were no missing data in the climatic datasets of March and April data (2020). At first, 43 stations meteorological data were collected from BMD. Then, these aggregated station-wise datasets were demarcated into eight divisional cities in this work. Finally, 8 divisional city data were averaged and used for further analysis. Data on daily confirmed and mortality cases from COVID-19 in March and April 2020 across Bangladesh, which can be found in the following link: https://corona.gov.bd. Until April 30, 2020 , the confirmed cases were 7674 , and deaths were 168 (IEDCR 2020). Weather variable data of Bangladesh in the study period were collected from BMD in the official site: https://bmd.gov.bd. 


\section{Calculation procedure of absolute humidity}

$\mathrm{AH}$ can be calculated from several formulas. One of them, the absolute humidity is estimated by the Eq. (1) (Snyder 2005):

$\mathrm{AH}=\frac{2165 e}{T_{\text {mean }}+273.16}$

where $\mathrm{AH}$ is the absolute humidity $\left(\mathrm{g} / \mathrm{m}^{3}\right), e$ is vapor pressure $(\mathrm{KPa})$, and $T_{\text {mean }}$ is the mean temperature $\left({ }^{\circ} \mathrm{C}\right)$. The detailed procedure of calculating vapor pressure can be found in the paper of Snyder (2005).

\section{Compound Poisson generalized linear model}

We employed the compound Poisson generalized linear model (CPGLMs) for exploring the relationship between daily meteorological variables (TDN, MT, NHR, MRH, AH, and rainfall), and daily confirmed cases from COVID-19 across Bangladesh from March 8 to April 30, 2020. First, meteorological variables were not considered during model development.

Most of the time-series data have continuous variables with exactly zero. To resolve this problem, a special form of the Poisson distribution should be implemented where the response is assumed to be generated as a random sum of individual random variables with positive support. Compound Poisson distribution, a mixture probability model takes this advantage to degenerate and continuous distribution found in the origin and positive real line, respectively. It is effective in which continuous data with exact zeros regularly arise. It handles effectively hierarchical structures or extra zero inflation. It is also a robust tool for the zero-inflated model (Zhang 2013).

The CPGLM function was established from the core model which was proposed by Jørgensen (1987) in the following Eq. (2):

$Y=\sum_{i=1}^{T} X_{i} \mathrm{~T} \sim$ pois $(\lambda), X_{i \sim}^{\text {lid }} \mathrm{Ga}(\alpha, \gamma), \mathrm{T} \perp X_{i}$

In the model, Pois () symbolizes a Poisson random variable with mean, and $\mathrm{Ga}($,) symbolizes a Gamma random parameter with mean and variance equal to and, respectively. $X_{i}$ is the identically distributed random variable. Here, if $T=0$ then $Y=$ 0 thereby allowing the distribution to have a probability mass at the origin. When $T>0$, the response parameter $Y$ is the sum of $T$ i.i.d Gamma random parameters, implying that $Y 1 T \mathrm{Ga}$ (,). In this study, Covid-19 confirmed cases set as the response parameter and all other weather parameters (TDN, MT, NRH, $\mathrm{MRH}, \mathrm{AH}$, and rainfall) were counted as independent parameters.

To visualize, the lag-wise effect of climatic variables on COVID-19 confirmed cases after developing the core model and then evaluated the probable lagged effects. In this case, we choose 9 days in 1 lag for single lag days (lag 0, days 1-9; lag 1, 10-18; lag 2, 19-27; lag 3, 28-36; lag 4, 37-45; and lag 5,
46-54) and cumulative days were selected in multiple-day lag (lag 1-5; lag 1, days 1-18; lag 2, 1-27; lag 3, 1-36; lag 4, 145; and lag 5, 1-54; March 8 to April 30 in calendar time). We removed lag 0 (days 1-9) in multiple days which represents a single -ay lag.

Both studies considered the lag from March 8 as before this date no mortality case was reported for considering lag days. This CPGLM analysis was performed in $\mathrm{R}$ (version 3.6.3) with 'cplm' (Version 0.7-8) package (Zhang 2013). Up to 0.05 was considered statistically significant. The effect was denoted as the slope changes and the coefficients of $95 \%$ significance levels of daily COVID-19 confirmed cases are in association with the climatic variables per 1-unit increase.

\section{Random forest model}

Breiman (2001) proposed the tree-based machine learning random forest (RF) model. It is applied for both predicting and regression problems. It is simple, as well as a robust model. RF model has been benefited from the two more powerful algorithms: bagging and random, which are called the powerhouse of this model. For developing the RF model number of trees and features in each split is essential. RF is a classifier, which comprises of an assortment of classifier trees $f_{m}(x)$ for $m=1, \ldots \ldots ., M$ which relies on the parameters and every single tree casts a unit vote for input $x$. Each tree generates an individual class, which then combined and the majority vote predicts the final results (Pavey et al. 2017). The RF model has been benefited from two more powerful algorithms: bagging and random, which are called the powerhouse of this model and combining with arcing. This model is robust for avoiding outliers alone with noise. The present study optimized its accuracy with 100 trees, 1 execution slot, 5 seeds, and with maximum depth 1 . This model was performed for this study by using the package of 'randomForest' within the free R statistical software. Several models exist, for instance, principal component analysis, which is used extensively for assessing the importance degree for the respective purposes. But now, scholars prefer machine learning algorithms of RF model for assessing the importance degree mainly in the fields of climate, hydrology, environment, etc. (Rahman and Islam 2019; Salam and Islam 2020; Saha et al. 2020). In this study, a RF model was used followed by Rahman an Islam et al. (2019), Salam and Islam (2020), Saha et al. (2020), Islam et al. (2020b) to explore the importance degree of climatic variables influencing COVID-19 mortality cases across eight major divisional cities of Bangladesh.

\section{Monte-Carlo method}

Monte-Carlo simulation refers to the method by which the percentage of risks can be represented by histograms (Cullen 2010). This is the most used model for identifying the 
contribution of risks on a particular factor. This analysis was based on the following Eq. (3) (Ökten 2005):

$X_{j}=b_{j}+\sum_{i_{1}=1}^{N} h_{\mathrm{ji}_{1}} b_{i_{1}}+\sum_{i_{2}=1}^{N} \sum_{i_{1}=1}^{N} h_{\mathrm{ji}_{2}} h_{i_{2} i_{1}} b_{i_{1}}+$,

where $X_{j}$ denotes the $j$ th elements of the solution vector; $h$ is the $N \times N$ matrix in jth element (e.g., $\left.h_{\mathrm{ji} 1}, h_{\mathrm{j} 12}\right)$ and $b_{i}$ is an $N$ dimensional vector satisfying condition.

Generally, the Monte-Carlo method can be summarized as below: (a) creating many random variables for each stochastic input; (b) according to a special statistical distribution, these random variables could be transformed into the associated random variates; (c) storing the obtained stochastic variates in an array for each variable; (d) each variable would create a value, which is used as a deterministic input in the computation formula of the meteorological variable; (e) computing the meteorological variables based on a numerical model for each Monte-Carlo run; (f) the outputs of the meteorological variables would be stored; (g) repeating steps (a)-(f) for detailed Monte-Carlo run; and (h) analyzing the computation outcomes. Monte-Carlo simulation is a robust tool to solve the randomness and uncertainty within model operations. A more detailed description of this model can be found in the paper of Ökten (2005). This study adopted this model for exploring the contribution percentage of climatic variables on the COVID-19 outbreak in Bangladesh.

\section{Results}

\section{Descriptive summaries}

Table 1 reveals the statistical summary of daily detected cases of the COVID-19 pandemic and meteorological variables in Bangladesh. A total of 7674 confirmed cases and 168 deaths were recorded during this study period (March 8-April 30) with an average of $142.1 \pm 195.5$ and $3.1 \pm 3.7$, respectively (IEDCR 2020). With the increasing rate of COVID-19 testing, the confirmed cases have also been increased over time. In this study, maximum $\left(T_{\max }\right)$ and minimum $\left(T_{\min }\right)$ temperatures ranged from 29.1 to $34.9^{\circ} \mathrm{C}$ and $16.2-24.8^{\circ} \mathrm{C}$ with their average of $32.2 \pm 1.3{ }^{\circ} \mathrm{C}$ and $20.9 \pm 1.9{ }^{\circ} \mathrm{C}$ respectively. TDN (diurnal temperature) had an average $11.3 \pm 1.9^{\circ} \mathrm{C}$ $\left(7.1-16.0^{\circ} \mathrm{C}\right)$ where the mean temperature (MT) was $26.6 \pm$ $1.3{ }^{\circ} \mathrm{C}\left(23.1^{\circ} \mathrm{C}-28.4^{\circ} \mathrm{C}\right)$. The relative humidity day (DRH) and night (NRH) period had an average of $69 \pm 8.7 \%$ and $61.6 \pm 10.7 \%$, respectively. However, the mean relative humidity (MRH) and AH ranged between 41.6 and $80.4 \%$ and $10.9-21.4 \mathrm{~g} / \mathrm{m}^{3}$, respectively. Apart from this, rainfall had an average of $3 \pm 5 \mathrm{~mm}(0.0-20.6 \mathrm{~mm})$ during the study period. Figure 3 shows the temporal distribution of COVID-19 daily confirmed cases and meteorological variables in Bangladesh during the investigation period, demonstrating the confirmed cases/day of COVID-19 distributed in a similar pattern with $\mathrm{NRH}, \mathrm{MRH}, \mathrm{AH}$, and rainfall, except for TDN and MT, where both variables showed an irregular pattern with the daily confirmed cases of the COVID-19 in Bangladesh.

\section{COVID-19 cases with the variation of meteorological factors}

Figure 4 reveals the temporal variations of meteorological factors at different eight divisions in Bangladesh. The TDN had the highest change in Sylhet $\left(19^{\circ} \mathrm{C}\right)$ followed by the lowest in Barishal division $\left(3^{\circ} \mathrm{C}\right)$. Rajshahi and Rangpur have substantial regional differences as $14.3{ }^{\circ} \mathrm{C}$ and $14.6{ }^{\circ} \mathrm{C}$, respectively. Alternatively, the largest and lowest MT value was found in Dhaka $\left(31.3^{\circ} \mathrm{C}\right)$ and Rangpur $\left(20.9{ }^{\circ} \mathrm{C}\right)$, respectively, where the most considerable differences were found in Dhaka divisional city $\left(22.9-31.3^{\circ} \mathrm{C}\right)$. In humidity, NRH and $\mathrm{AH}$ both cases, the highest and lowest values were found in Barishal $\left(98.3 \%\right.$ and $\left.25.4 \mathrm{~g} / \mathrm{m}^{3}\right)$ and Sylhet $(31.5 \%$ and $8.5 \mathrm{~g} /$ $\mathrm{m}^{3}$ ), respectively. The highest range value was found for $\mathrm{NRH}$ and AH in Rangpur (34.8-95.5\%) and Barishal (11.1-25.4 g/ $\mathrm{m}^{3}$ ), respectively. In MRH, the highest value and range were observed in the Rangpur division (93.5\% and 41.3-93.5\%), where the lowest value was in Dhaka (35\%). In the rainfall variables, many outliers were detected in Rajshahi, Rangpur, Khulna, and Barishal divisions. The lowest rainfall was observed at the Rajshahi division (2 $\mathrm{mm})$, whileThe highest rainfall was distributed at Barishal division $(38.5 \mathrm{~mm})$.

\section{COVID-19 mortality with variability in meteorological factors using CPGLM modeling}

Figure 5 shows the slope changes of COVID-19 confirmed counts per 1-unit elevation in climatic factors with various lags (0-5) using the CPGLMs modeling. In single lag, both per 1 unit raise in all factors such as MT, NRH, MRH, AH, and rainfall, except for TDN were connected to increased COVID-19 confirmed cases in lag 0 , with the highest increase (26.5\% (95\% CI $142.13 \%,-89.13 \%) ; 8.91 \%$ (95\% CI $37.80 \%,-19.98 \%$ ); $11.39 \%$ (CI $34.47 \%,-11.71 \%$ ); $62.4 \%$ (95\% CI $186.14 \%,-61.34 \%$ ); and $83.22 \%$ (95\% CI $365.46 \%,-199.02 \%)]$ respectively. As for TDN each $1{ }^{\circ} \mathrm{C}$ increase was associated with a $2.22 \%(95 \%$ CI $24.6 \%$, $20.17 \%$ ) rise in COVID-19 confirmed counts in only lag 5. In contrast, in the case of multiple lags, each 1 unit increase in MT and AH was the highest association with $77.54 \%$ (95\% CI $112.84 \%, 42.24 \%)$ and $67.77 \%$ (95\% CI $80.81 \%, 54.73 \%)$ enhancement in the COVID-19 confirmed counts in both lag 5 (Fig. 6). A $1 \mathrm{~mm}$ increase in rainfall raised by $30.99 \%$ (95\% CI $77.18 \%,-15.20 \%)$ COVID-19 confirmed cases while an increase of $1{ }^{\circ} \mathrm{C}$ of TDN declined the confirmed cases by $14.2 \%$ (95\% CI $9.73 \%,-38.13 \%$ ) on the lag 1 and lag 2, respectively. NRH and MRH had the highest increase 
Table 1 Statistical summary of COVID-19 variables and meteorological factors in Bangladesh

\begin{tabular}{|c|c|c|c|c|c|c|c|c|c|c|c|}
\hline Variables & Mean \pm S.D. & Std. Error of Mean & Median & Mode & Minimum & Maximum & Skewness & Kurtosis & P 25 & P 50 & P 75 \\
\hline Max temp $\left({ }^{\circ} \mathrm{C}\right)$ & $32.2 \pm 1.3$ & 0.2 & 32.2 & 31.9 & 29.1 & 34.9 & -0.1 & 0.0 & 31.5 & 32.2 & 33.0 \\
\hline Min temp $\left({ }^{\circ} \mathrm{C}\right)$ & $20.9 \pm 1.9$ & 0.3 & 21.4 & $21.3^{\mathrm{a}}$ & 16.2 & 24.8 & -0.3 & -0.5 & 19.2 & 21.4 & 22.5 \\
\hline Diurnal temp $\left({ }^{\circ} \mathrm{C}\right)$ & $11.3 \pm 1.9$ & 0.3 & 11.5 & 11.5 & 7.1 & 16.0 & 0.1 & -0.4 & 9.8 & 11.5 & 12.8 \\
\hline Mean temp $\left({ }^{\circ} \mathrm{C}\right)$ & $26.6 \pm 1.3$ & 0.2 & 26.9 & 26.8 & 23.1 & 28.4 & -0.7 & -0.2 & 25.8 & 26.9 & 27.6 \\
\hline Day RH & $69 \pm 8.7$ & 1.2 & 70.0 & 76.3 & 46.2 & 82.9 & -0.6 & 0.2 & 64.6 & 70.0 & 76.3 \\
\hline Night RH & $61.6 \pm 10.7$ & 1.5 & 59.9 & $54.3^{\mathrm{a}}$ & 38.4 & 86.7 & 0.3 & -0.2 & 54.5 & 59.9 & 69.9 \\
\hline Mean RH & $64.2 \pm 9.1$ & 1.2 & 63.4 & $60.3^{\mathrm{a}}$ & 41.6 & 80.4 & -0.2 & -0.1 & 58.7 & 63.4 & 72.1 \\
\hline Absolute Humidity & $16.5 \pm 2.8$ & 0.4 & 16.4 & 19.9 & 10.9 & 21.4 & -0.1 & -0.9 & 14.4 & 16.4 & 19.0 \\
\hline Rainfall & $3 \pm 5$ & 0.7 & 0.3 & 0.0 & 0.0 & 20.6 & 2.1 & 3.8 & 0.0 & 0.3 & 3.5 \\
\hline Mortality & $3.1 \pm 3.7$ & 0.5 & 1.0 & 0.0 & 0.0 & 15.0 & 1.1 & 0.5 & 0.0 & 1.0 & 5.3 \\
\hline Confirmed & $142.1 \pm 195.5$ & 26.6 & 7.5 & 0.0 & 0.0 & 641.0 & 1.1 & -0.2 & 2.0 & 7.5 & 306.8 \\
\hline
\end{tabular}

Multiple modes exist. The smallest value is shown

(17.98\% (95\% CI $22.5 \%, 13.42 \%)$ and $19.92 \%$ (95\% CI $25.71 \%, 14.13 \%)$ ) of COVID-19 cased in lag 4.

\section{Contribution analysis of meteorological variables based on Monte-Carlo simulation}

The Monte-Carlo simulation method was used to identify the most influential meteorological variables that affect COVID19 confirmed cases of count and contribute most to the total COVID-19 mortality cases over Bangladesh (Fig. 7). The results indicated that among the nine climatic variables, the most driving variable was NRH, which had a score of 0.33 . The second and third most influential variables were the MRH, and DRH, which had a score of 0.26 and 0.24 , respectively. The other meteorological variables such as rainfall, absolute AH, MT, TDN, $T_{\min }$, and $T_{\max }$ had less than 0.25 score, which was comparatively non-significant.

\section{Role of influencing meteorological factors on COVID- 19 mortality cases based on RF model}

To perform the significance degree analysis for the contributing meteorological factors, RF tool was applied. It assisted for determining the order of contribution status of several climatic

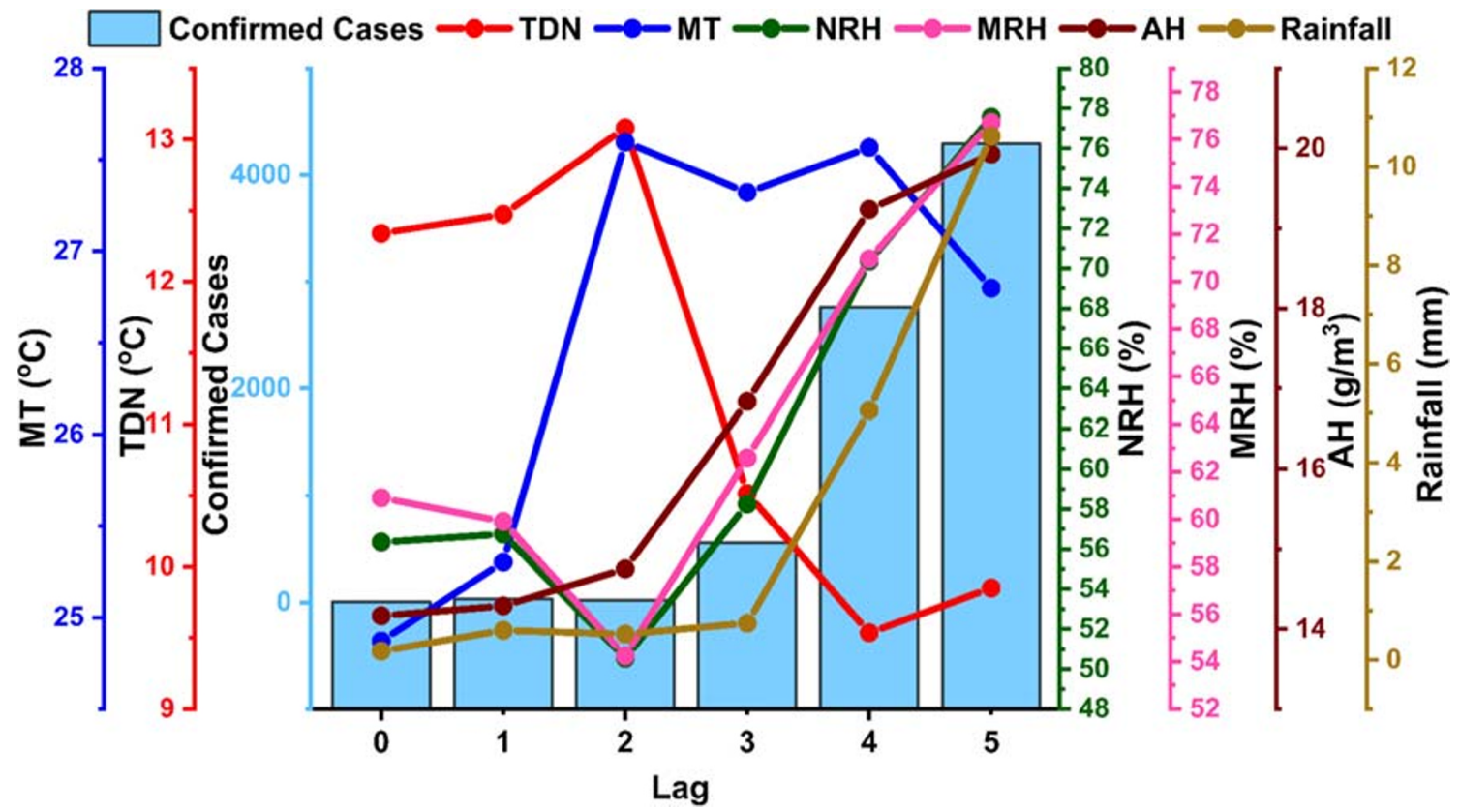

Fig. 3 Temporal distributions of COVID-19 daily confirmed cases and climatic variables in Bangladesh from March 8 to April 2020. COVID19, corona virus disease-2019; TDN, diurnal temperature; MT, mean temperature; $\mathrm{NRH}$, night relative humidity; MRH, mean relative

humidity; AH, absolute humidity; lag $0=$ days $1-9$, lag 1 = days 10 18 , lag $2=$ days $19-27, \operatorname{lag} 3=$ days $28-37$, lag $4=$ days $36-45$, and lag 5 $=$ days $46-54$ 

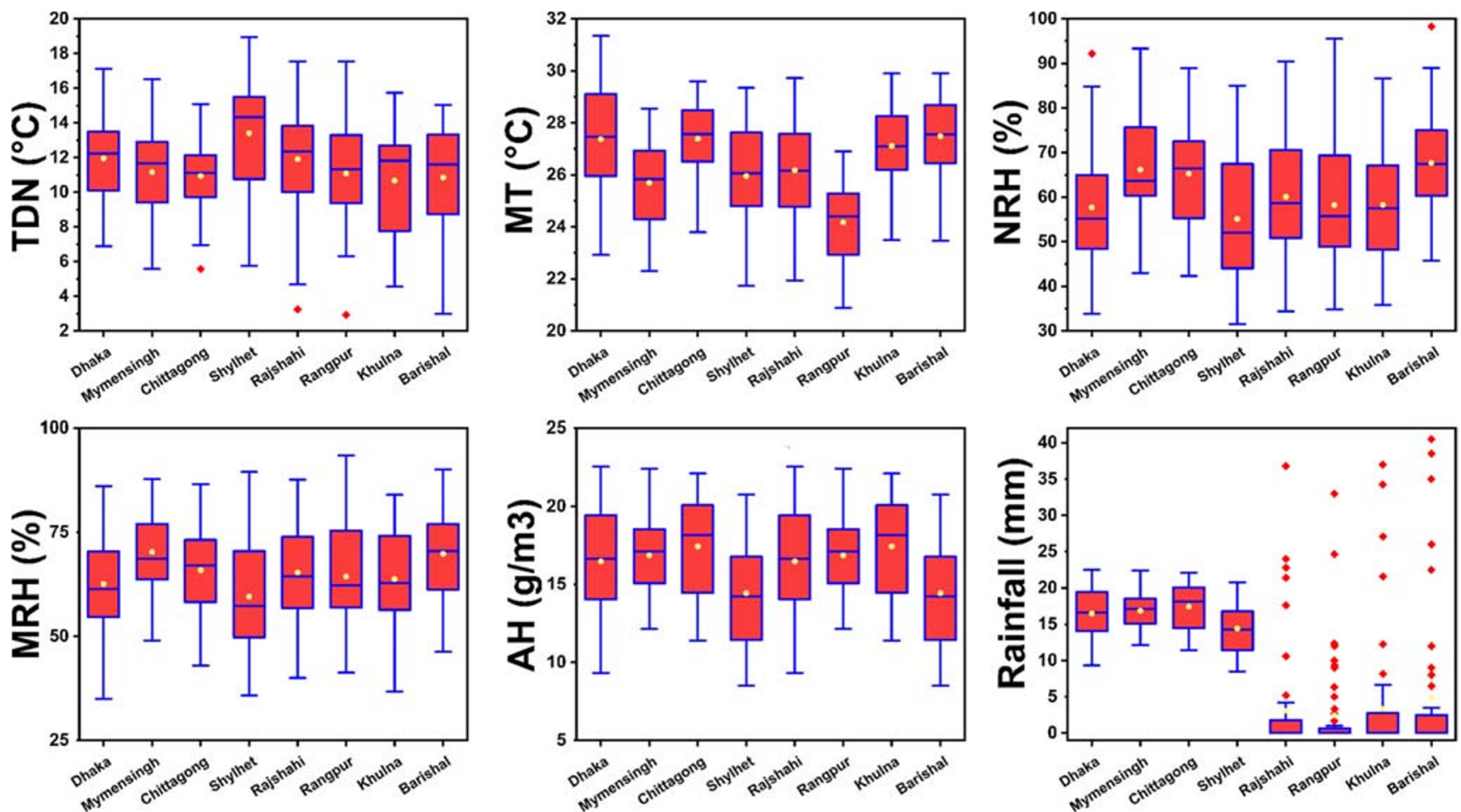

Fig. 4 Temporal variation of meteorological variables in eight divisions of Bangladesh. Boxplots represent the distance between the first and third quartiles while whiskers are set as the most extreme (lower and upper)

data point where the yellow and red points represent median and outliers respectively
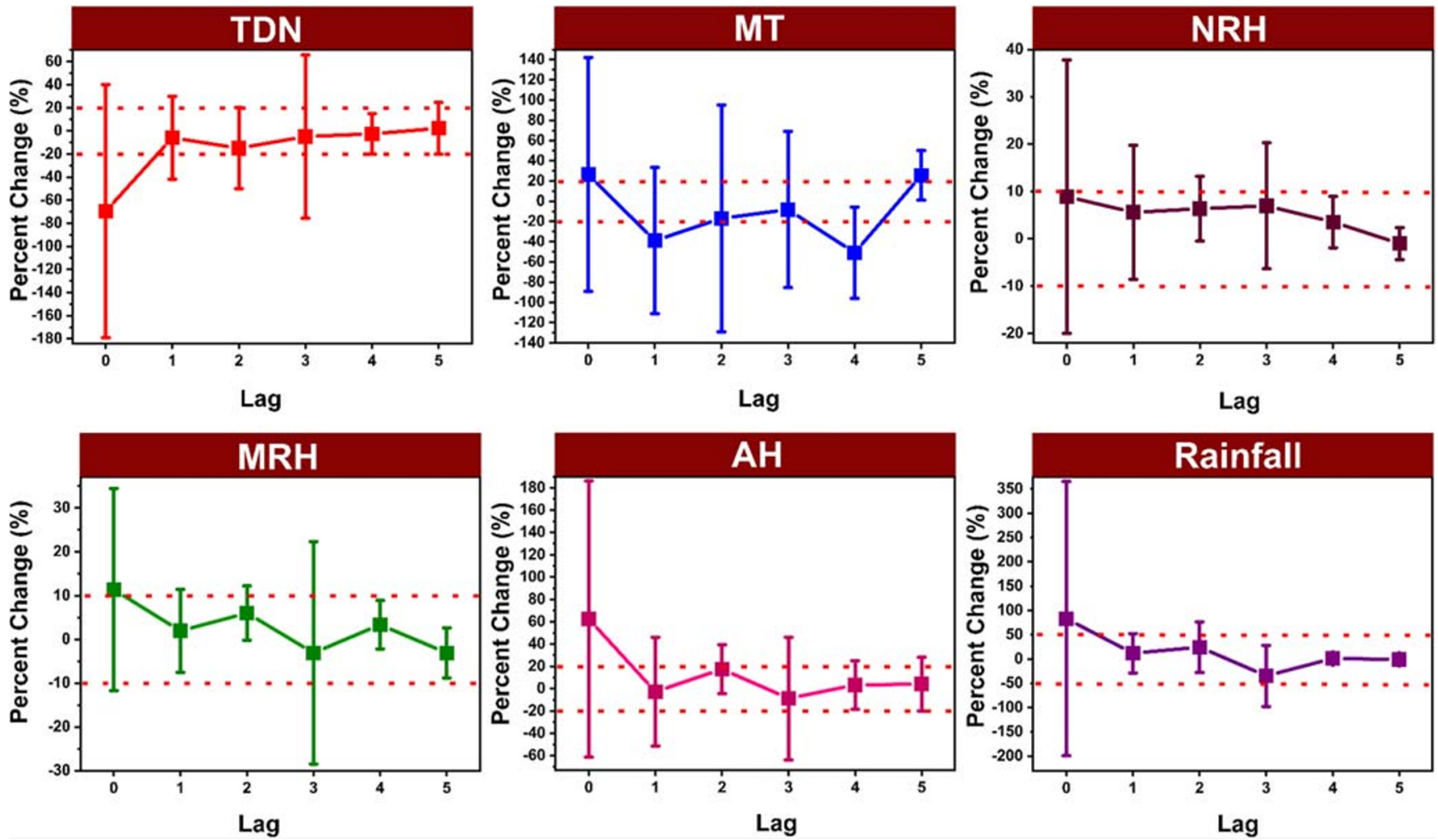

Fig. 5 The association of slope changes between COVID-19 daily confirmed cases with 1-unit increase in meteorological factors for the effects of singlelag days based on the CPGLM models across Bangladesh at $95 \%$ confidence interval 

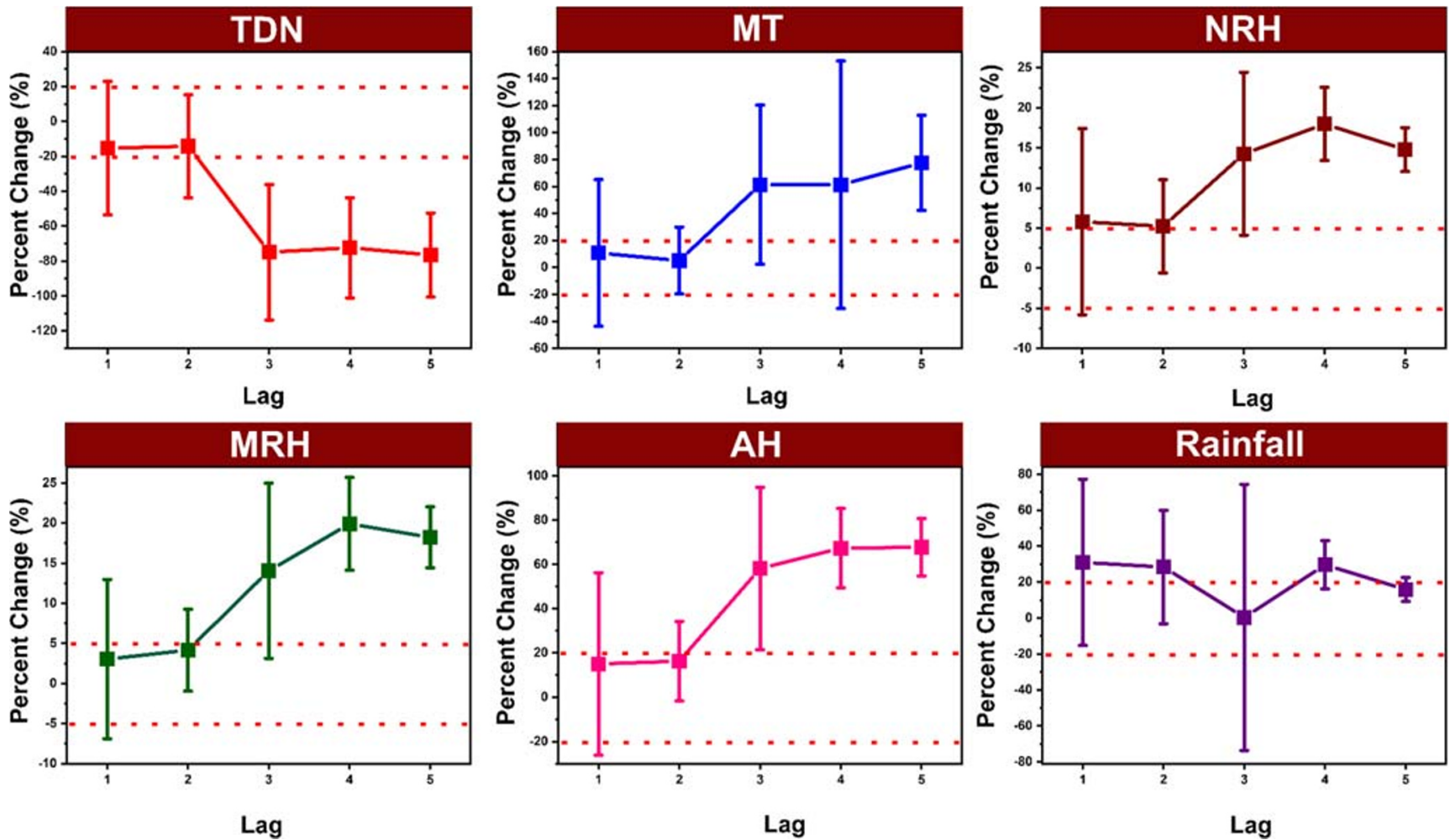

Fig. 6 The association of slope changes between COVID-19 daily confirmed cases with 1-unit increase in meteorological factors for the effects of multiple-lag days based on the CPGLM models across Bangladesh at $95 \%$ confidence interval

variables affecting the COVID-19 mortality cases based on the RFM model in 8 divisions across Bangladesh (Fig. 8).

The yellow and light green columns of the histogram showing the TDN and AH, respectively. TDN and AH found as the highest contributing variables, indicating that these two variables influence the COVID-19 cases most in 5 divisions of Mymensingh, Rangpur, Sylhet, Barishal, and Chattogram
(Table 2 and Fig. 8). Table 2 depicts that among the eight divisions of Bangladesh, three divisions show TDN and three divisions represent $\mathrm{AH}$ as the highest contributing factor. $\mathrm{AH}$ comprised almost $37.5 \%$ of 8 divisions, which were identified mostly in northeastern (Mymensingh), followed by northern (Rangpur) and southwestern coastal climatic regions (Khulna). In addition, TDN consisted of nearly $37.5 \%$ of the
Fig. 7 Contribution percentage of meteorological factors on COVID-19 outbreak in Bangladesh using Monte-Carlo simulation

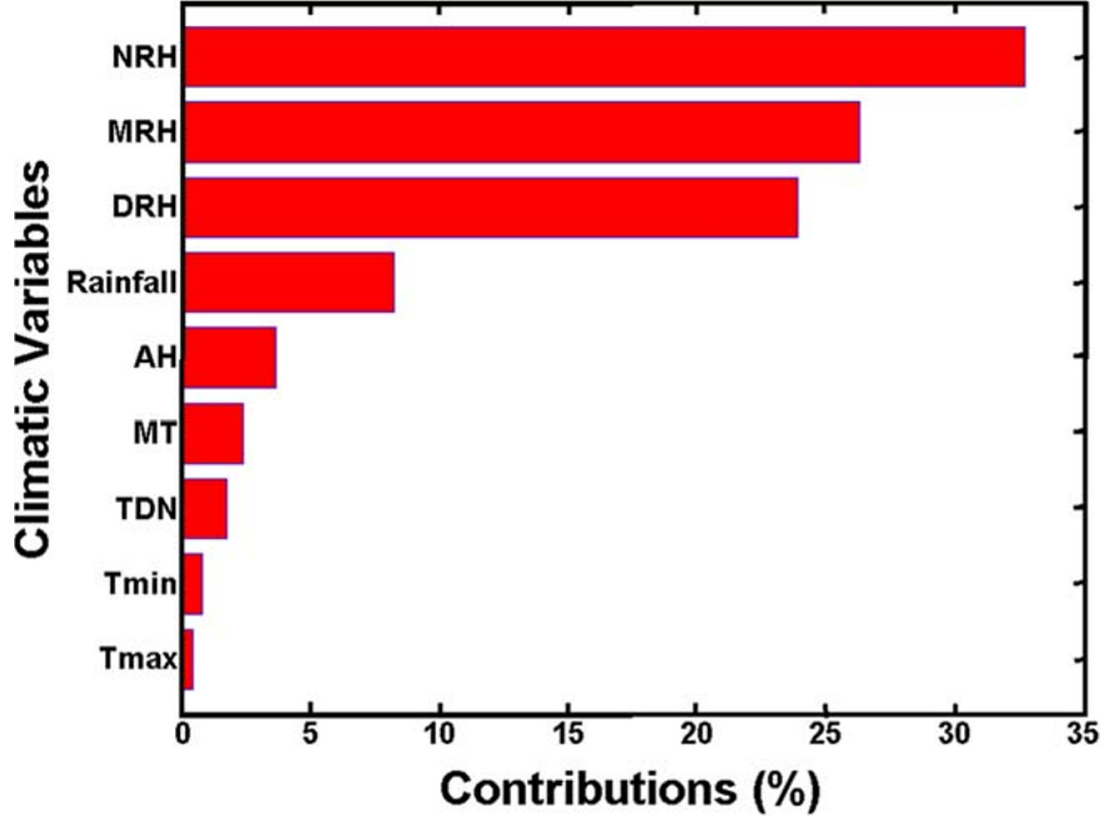


total area, which was detected mainly in the eastern (Sylhet), followed by southcentral (Barishal) and southeastern (Chattogram). MRH was to be found as the second-highest contributing variable affecting 50\% of the total COVID-19 mortality cases distributed mostly in northeastern regions (Mymensingh), eastern (Sylhet), southcentral (Barishal), and southwestern (Khulna) of Bangladesh (Fig. 8). It is observed that MT and rainfall are the lowest contributing variables in

\section{Climatic variables}

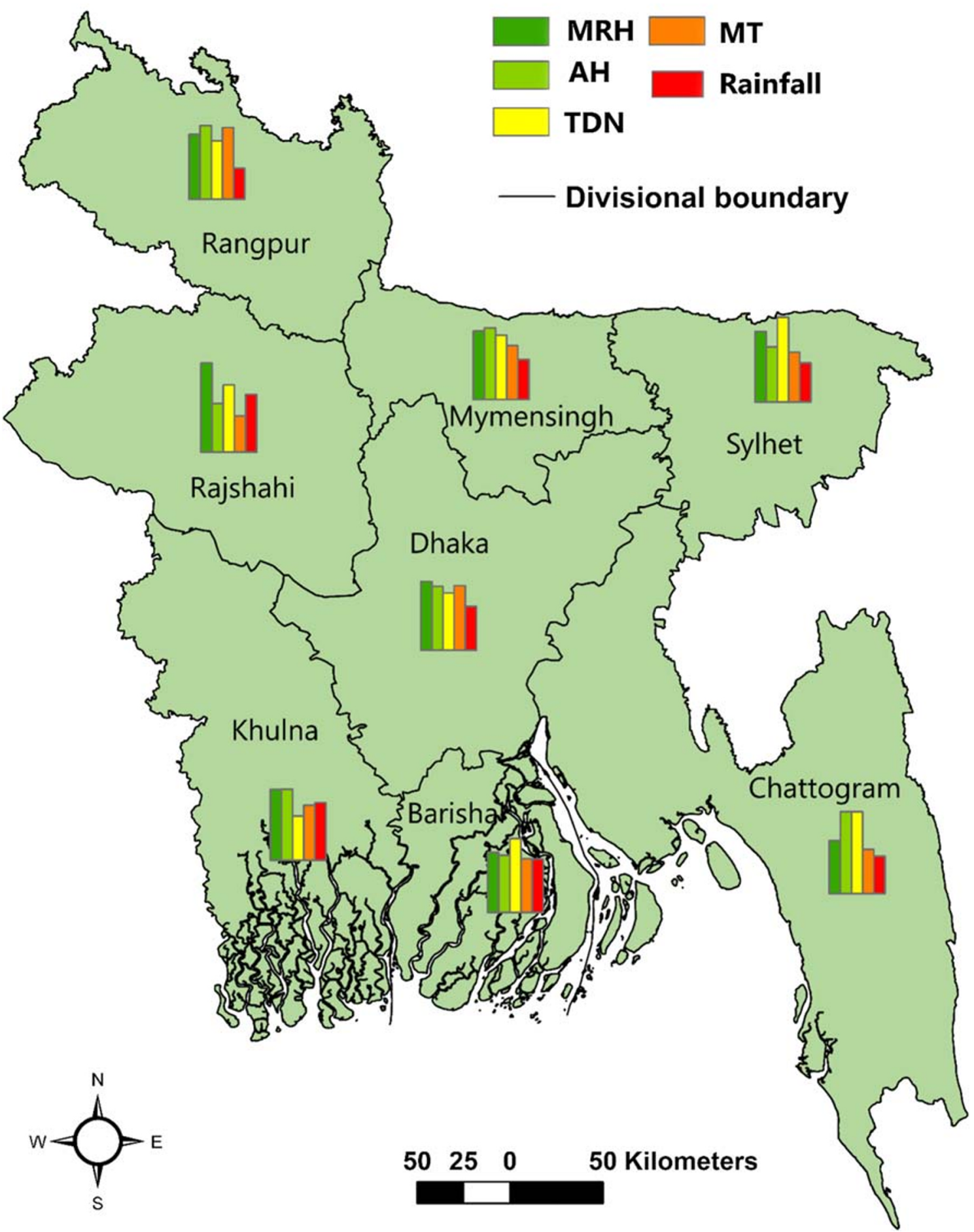

Fig. 8 Bar diagram in the map shows the importance degree of climatic variables on COVID-19 confirm cases in eight division of Bangladesh from March 8, 2020 to 30 April 30, 2020 
Table 2 Importance degree of meteorological variables on COVID-19 confirm cases in eight divisions of Bangladesh during March 8, 2020 to April 30, 2020 using random forest model

\begin{tabular}{lllll}
\hline Division & $\begin{array}{l}\text { First largest } \\
\text { contributing variable }\end{array}$ & Importance degree & $\begin{array}{l}\text { Second largest } \\
\text { contributing variable }\end{array}$ & Importance degree \\
\hline Dhaka & MRH & 22.94 & MT & 21.58 \\
Mymensingh & AH & 24.01 & MRH & 22.91 \\
Rajshahi & MRH & 29.83 & TDN & 22.47 \\
Rangpur & AH & 24.58 & MT & 23.91 \\
Khulna & AH & 23.79 & MRH & 23.68 \\
Sylhet & TDN & 28.38 & MRH & 23.53 \\
Barishal & TDN & 24.74 & MRH & 20.13 \\
Chittagong & TDN & 27.43 & AH & 27.42 \\
\hline
\end{tabular}

$M R H$, mean relative humidity; $A H$, absolute humidity; $T D N$, diurnal temperature; $M T$, mean temperature affecting the daily mortality cases. In the Dhaka division, MRH is the most vital factor that affects COVID-19 deaths. Therefore, the results imply that AH, TDN, and MRH are the key contributing climatic variables for daily COVID-19 cases across Bangladesh.

\section{Discussion}

The role of MT and RH in day-to-day new infections and case fatalities due to COVID-19 should be dealt with many other possible and unprecedented controlling factors which are not yet established. For instance, the potential factors such as wind (speed and direction), national population age groupings, the density of population, and global indices (Global Health Security Index; GHSI, and human development index; HDI) should be considered the confounding factors for the COVID19 transmission (Wu et al. 2020). Meteorological factors such as humidity, temperature, and rainfall are critical drivers for controlling infectious diseases in different parts of the world (Sahin 2020; Islam et al. 2020c). For example, elevated temperatures may prevent the outbreak of droplets that transmit coronavirus, likely via rapid evaporation. Simultaneously, other factors like humidity may enhance the COVID-19 survival time in atmosphere possibly also influence the infection rate, which is shown in Fig. 5. These outcomes can be considered with caution. Previous studies indicate that humidity affects the infection rates of COVID-19 outbreak (Oliveiros et al. 2020; Wu et al. 2020; Demongeot et al. 2020; Wang et al. 2020). It is unknown whether increases in seasonal temperatures will decrease the rate, which deserves further investigation. In fact, to date, role of environmental factors in the transmission of COVID-19 is not established. Concrete and evidenced-based proofs are needed to be explored, besides the probabilistic determination methods could help to obtain potential clues.

We run a CPGLM, permitting us for parameters specific to the contagious SARS-CoV perspectives (Imai et al. 2015).
However, these drivers may behave differently for the daily mortality cases due to infectious diseases in different climatic zones as well as socio-demographic settings. For example, in tropical Brazil, high mean temperature and intermediate $\mathrm{RH}$ may be responsible for the COVID-19 outbreak (Auler et al. 2020), and the current disease situation in this country is the worst with severe death tolls. In Turkey, the key weather factors might control the spread of COVID-19 is considered temperature $\left({ }^{\circ} \mathrm{C}\right)$, dew point $\left({ }^{\circ} \mathrm{C}\right)$, humidity $(\%)$, and wind speed (mph). Due to variant incubation periods of COVID-19 (1 to 14 days), Spearman's correlation coefficients revealed that wind speed and temperature had a direct relationship with COVID-19 cases in Turkey (Sahin 2020).

Ma et al. (2020) reported that RH had a reverse association with COVID-19 mortality cases/day $(r=-0.32)$, with the highest reduction in lag $3(-11.41 \%$ (95\% CI $-19.68 \%$, $2.29 \%$ ). Another study stated that every $1 \%$ rise in $\mathrm{RH}$, confirmed cases/days of COVID-19 lowered by $0.85 \%$ (with the CI $95 \%, 0.51 \%, 1.19 \%$ ), and mortality/day lowered by $0.51 \%$ (95\% CI $0.34 \%, 0.67 \%$ ) in the 166 countries (Wu et al. 2020). Contrary to these cited works, our result found that in the single-lag days, every $1 \%$ rise in mean $\mathrm{RH}$, confirmed case/ day of the COVID-19 raised by $11.39 \%$ (CI $34.47 \%$, $11.71 \%$ ) in Bangladesh. Similarly, every $1 \mathrm{~mm}$ increase in rainfall elevated by $30.99 \%$ (95\% CI $77.18 \%,-15.20 \%$ ) COVID-19 cases in lags 1 and 2. The conflicting outcomes may be due to their studies were conducted at the global scale, and the temperature and humidity ranges were large and different climatic and geographic settings. However, in either case, more studies are warranted to draw a precise conclusion to assure the contribution of meteorological impacts on COVID-19 cases.

A recent study in China stated that daily COVID-19 cases elevated by $4.861 \%$ for every $1{ }^{\circ} \mathrm{C}$ increase in MT (Zhu and Xie 2020) when the MT was fallen $3{ }^{\circ} \mathrm{C}$. This result echoes our outcomes. Each $1{ }^{\circ} \mathrm{C}$ increase in MT was corroborated with the elevated COVID-19 confirmed cases in lag 0, with the highest growth of $26.5 \%$ (95\% CI $142.13 \%,-89.13 \%$ ), 
but it should be kept in mind that this increased transmission majorly comes from contact and community media. Ma et al. (2020) explored the daily mortality of COVID-19 in Wuhan, China. They found that diurnal temperature ranges had a significant positive association with daily COVID-19 mortality, which is in disagreement with our study. However, this result was unstable because the temperature was associated with a decline in COVID-19 mortality in lags 3 and 5. The other reason is that they may be used in the various characteristics of the participants and multiple methods (Prata et al. 2020).

The probable elucidation of our results is that meteorological factors such as temperature, humidity, and rainfall are critical factors in living conditions that play a vital role in the status of human health according to pandemic induction and prevention (McMichael et al. 2008; Salam et al. 2019). A set of definite meteorological factors that suitable fits favor coronavirus and that specific climatic variables like humidity contribute to the outbreak because it exists when the susceptibility rises. It clearly indicates about the virus particle survival state under variant meteorological conditions rather than direct transmission. Therefore, the onset of summer can be favorable to enhance the spread out of the COVID-19 cases. Our findings accord with those published cited reported worldwide, exhibiting how the number of confirmed cases increases above $25{ }^{\circ} \mathrm{C}$ and linearly increased afterward. Several studies have stated that the virus (SARS-CoV-2) is sensitive to temperature and humidity (Luo et al. 2013; Ma et al. 2020; Sajadi et al. 2020; Liu et al. 2020; Benvenuto et al. 2020; Tobías and Molina 2020).

Moreover, a recent study by Benvenuto et al. (2020) showed that the variability of SARS-CoV-2 was similar to that of SARS-CoV under different experimental settings. Chan et al. (2011) showed that the temperature up to $25^{\circ} \mathrm{C}$ and relative humidity of more than $50 \%$, dried out SARS-CoV could survive for more than 1 week on smooth surfaces. However, the stability of SARS-CoV increased when the relative humidity and rainfall increased. The SARS-CoV-2 might be more stable at high-rainfall and high-humid conditions. The moisture in the bioaerosols evaporates quickly in high relative humidity, creating a tiny droplet in the air for a long time, thereby enhancing the probability of pathogen outbreak (Tellier 2006). However, our immunity system is not compromised in high-humidity systems (Oliveiros et al. 2020). Thus, the human body is at an elevated risk of infection by viruses in high-temperature, high-rainfall, and high-humid conditions.

In this study, the change in daily COVID-19 cases has a strong association with $\mathrm{AH}$ and $\mathrm{RH}$, which move southward to increase easterlies. Our findings showed that the overall COVID-19 pandemic in Bangladesh can be affected by the change of humidity mostly. Many studies have reported that temperature and relative humidity are the most contributing climatic variables influencing COVID-19 cases in other countries (Ma et al. 2020; Shi et al. 2020). This study also is confirmed that five meteorological variables included, where $\mathrm{AH}$ and DT are the most contributing factor, and the RH is the second-highest influencing factor in the variability of daily COVID-19 cases. Ma et al. (2020) found that a positive association is found between daily death counts of COVID-19 and TDN.

Contrary to our study, Zhu and Xie (2020) reported that case counts of COVID-19 could decline when the weather becomes warmer when the temperature is above $3{ }^{\circ} \mathrm{C}$. The possible key meteorological driver of the COVID-19 mortality cases in Bangladesh might be the $\mathrm{AH}$ and $\mathrm{RH}$ as well as other climatic factors such as TDN, MT, and rainfall (Oliveiros et al. 2020; Qi et al. 2020b; Shi et al. 2020; Wu et al. 2020; Zhu and Xie 2020). The RF model showed that MT and rainfall are the lowest contributing factors affecting the daily mortality cases in Bangladesh. In the Dhaka division, MRH is the most vital factor that affects COVID-19 deaths.

The findings of Wu et al. (2020) provided preliminary insights for the potential association between the virus and the climatic parameters. Whatever is the association being, there is no alternative to control the infections, transmissions, and therefore spread of COVID-19. A possible mechanism of particulate matter PM10 concentration upon COVID-19 diseases was evaluated in Italy, considering the airborne virus diffusion based on PM10 as a vector. COVID-19 infection cases can influence the association between air pollutants and humaninduced aerosols. However, direct correlations between the presence of high quantities of PM10 and the diffusion of the COVID-19 virus were not evident (Bontempi 2020).

Though our study gives a strong clue to meteorological factors that might have an association with COVID-19 confirmed cases and mortality, the following limitations are observed. First, other variables such as environmental pollutants, air quality, and UV radiations must perform a comprehensive study of COVID-19 infectious disease. Second, the association of PM2.5, air pollutants, and human-induced aerosols may be influenced by the COVID-19 infection cases. Next, many parameters including immunity, social and physical distancing, nutritional status, and accessibility of healthcare facilities affect the COVID-19 cases/mortality (Shammi et al. 2020a, 2020b). This study did not consider socioeconomic factors such as population movement and population density. Finally, epidemiological data should be dealt with more cautiously and systematically to differentiate the number of infected cases and local death rates require to be deserved in further investigation. In the entire Bangladesh, air quality index, along with other factors, should be considered to risk assessment on daily new cases of infections and mortality. Policymakers should think about the meteorological variables, especially AH and RH along with environmental factors such as air pollution for taking necessary measures to manage and prevent new infections. 


\section{Conclusion}

We found that the confirmed cases of COVID-19 were distributed in a similar pattern with meteorological factors such as NRH, MRH, AH, and rainfall except for TDN and MT, where both the factors showed an irregular pattern with the daily confirmed cases of the COVID-19 in Bangladesh. The result also disclosed that both per 1 unit increase in NRH, MRH, $\mathrm{AH}$, and rainfall were related to the increased COVID-19 confirmed cases in lag 0, with the highest increase $(8.91 \%$ (95\% CI $37.80 \%,-19.98 \%$ ); $11.39 \%$ (CI $34.47 \%,-11.71 \%$ ); $62.4 \%$ (95\% CI $186.14 \%,-61.34 \%$ ); and $83.22 \%$ (95\% CI $365.46 \%$,$199.02 \%)$ ) respectively. In contrast, in the case of multiple lags, NRH and MRH had the highest increase $(17.98 \%$ (95\% CI $22.5 \%, 13.42 \%)$ and $19.92 \%$ (95\% CI $25.71 \%$, $14.13 \%)$ ) of COVID-19 cased in lag 4 while $1 \mathrm{~mm}$ increase in rainfall elevated by $30.99 \%$ (95\% CI $77.18 \%,-15.20 \%$ ) COVID-19 infections on lag 1 and lag 2 respectively. The humidity (NRH, MRH, DRH) and rainfall are the most influential meteorological factors to the COVID-19 cases. In the Dhaka division, the mean relative humidity is the most vital factor that affects COVID-19 cases. The outcomes of the RF model demonstrated that the humidity and diurnal temperature are vital factors influencing the COVID-19 confirmed cases. As infection cases are still rising in Bangladesh, this study recommends that sectoral policies, actions, and preventive measures should be implemented considering the environmental factors to reduce transmission and strengthen the healthcare system in Bangladesh. The Government will not capable to alleviate this worse situation alone, specific efforts from the people, active participation of the country's healthcare specialists, and international aid are immediately required.

Acknowledgments We greatly acknowledge the Bangladesh Meteorological Department (BMD) for providing the required datasets during the observation period. We are also thankful to the anonymous reviewer for the improving quality of the manuscript.

Authors' contributions A.R.M. T.I. and M.H. designed, planned, conceptualized, and drafted the original manuscript; aH.S. and R.S were involved in statistical analysis and interpretation; M.B. and M.M.R contributed instrumental setup, data analysis, and validation; M.S., M.A.M., and S.H. contributed to editing the manuscript, literature review, and proofreading; M.M.R., M.S., and A.R.M. T.I. were involved in software, mapping, and proofreading during the manuscript drafting stage.

Data availability Data are available upon request from the corresponding author.

\section{Compliance with ethical standards}

Conflict of interest The authors declare that they have no conflict of interest.

\section{References}

Auler AC, Cassaro FAM, da Silva VO, Pires LF (2020) Evidence that high temperatures and intermediate relative humidity might favor the spread of COVID-19 in tropical climate: a case study for the most affected Brazilian cities. Sci Total Environ 729:139090. https://doi.org/10.1016/j.scitotenv.2020.139090

Barreca AI, Shimshack JP (2012) Absolute humidity, temperature, and influenza mortality: 30 years of county-level evidence from the United States. Am J Epidemiol 176(Suppl 7):S114-S122. https:// doi.org/10.1093/aje/kws259

Benvenuto D, Giovanetti M, Ciccozzi A, Spoto S, Angeletti S, Ciccozzi M (2020) The 2019-new coronavirus epidemic: evidence for virus evolution. J Med Virol 92:455-459

Bodrud-Doza M, Shammi M, Bahlman L, Islam ARMT, Rahman MM (2020) Psychosocial and socio-economic crisis in Bangladesh due to COVID-19 pandemic: a perception-based assessment. Front Public Health 8:341. https://doi.org/10.3389/fpubh.2020.00341

Bontempi E (2020) First data analysis about possible COVID-19 virus airborne diffusion due to air particulate matter (PM): the case of Lombardy (Italy). Environ Res 186:109639. https://doi.org/10. 1016/j.envres.2020.109639

Breiman L (2001) Random forests. Mach Learn 45(1):5-32. https://doi. org/10.1023/A:1010933404324

Chan KH, Peiris JSM, Lam SY, Poon LLM, Yuen KY, Seto WH (2011) The effects of temperature and relative humidity on the viability of the SARS coronavirus. Adv virol:734690-734690. https://doi.org/ $10.1155 / 2011 / 734690$

Cullen A (2010) Monte Carlo simulation for quantitative health risk analysis. Wiley Encyclopedia of Operations Research and Management Science

Demongeot J, Flet-Berliac Y, Seligmann H (2020) Temperature decreases spread parameters of the new COVIDd-19 case dynamics. Biology 9:94

Imai C, Armstrong B, Chalabi Z, Mangtani P, Hashizume M (2015) Time series regression model for infectious disease and weather. Environ Res 142:319-327

Institute of Epidemiology, Disease Control and Research (IEDCR) (2020) Covid-19 Status Bangladesh. https://www.iedcr.gov.bd/ (Accessed 6 May 2020)

Islam ARMT, Shen S, Yang SB, Hu Z, Chu R (2019) Assessing recent impacts of climate change on design water requirement of Boro rice season in Bangladesh. Theor Appl Climatol 138:97-113. https://doi. org/10.1007/s00704-019-02818-8

Islam ARMT, Rahman MS, Khatun R, Hu Z (2020a) Spatiotemporal trends in the frequency of daily rainfall in Bangladesh during 1975-2017. Theor Appl Climatol. https://doi.org/10.1007/s00704020-03244-x

Islam ARMT, Ahmed I, Rahman MS (2020b) Trends in cooling and heating degree-days overtimes in Bangladesh? An investigation of the possible causes of changes. Nat Hazards 101:879-909. https:// doi.org/10.1007/s11069-020-03900-5

Islam ARMT, Hasanuzzaman M, Azad MAK, Salam R, Toshi FZ, Khan MSI, Alam GMM, Ibrahim SM (2020c) Effect of meteorological factors on COVID-19 cases in Bangladesh. Environ Dev Sustain. https://doi.org/10.1007/s10668-020-01016-1

Jørgensen B (1987) Exponential dispersion models (with discussion). J R Stat Soc B 49:127-162

Kramer SC, Shaman J (2019) Development and validation of influenza forecasting for 64 temperate and tropical countries. PLoS Comput Biol 15(2):e1006742. https://doi.org/10.1371/journal.pcbi.1006742

Kudo E, Song E, Yockey LJ, Rakib T, Wong PW, Homer RJ, Iwasaki A (2019) Low ambient humidity impairs barrier function and innate resistance against influenza infection. Proc Natl Acad Sci U S A 116(22):10905-10910. https://doi.org/10.1073/pnas.1902840116 
Liu J, Zhou J, Yao J, Zhang X, Li L, Xu X, He X, Wang B, Fu S, Niu T, Yan J (2020) Impact of meteorological factors on the COVID-19 transmission: a multi- city study in China. Sci Total Environ 726: 138513

Luo Y, Zhang Y, Liu T, Rutherford S, Xu Y, Xu X, Wu W, Xiao J, Zeng $\mathrm{W}$, Chu C, Ma W (2013) Lagged effect of diurnal temperature range on mortality in a subtropical megacity of China. PLoS One 8(2): e55280. https://doi.org/10.1371/journal.pone.0055280

Ma Y, Zhao Y, Liu J, He X, Wang B, Fu S, Luo B (2020) Effects of temperature variation and humidity on the death of COVID-19 in Wuhan, China. Sci Total Environ 138226. https://doi.org/10.1016/j. scitotenv.2020.138226

Marr LC, Tang JW, Van Mullekom J, Lakdawala SS (2019) Mechanistic insights into the effect of humidity on airborne influenza virus survival, transmission and incidence. J R Soc Interface 16(150): 20180298. https://doi.org/10.1098/rsif.2018.0298

McMichael AJ, Wilkinson P, Kovats RS, Pattenden S, Hajat S, Armstrong B, Vajanapoom N, Niciu EM, Mahomed H, Kingkeow C, Kosnik M (2008) International study of temperature, heat and urban mortality: the 'ISOTHURM' project. Int J Epidemiol 37: 1121-1131

Murtas R, Russo AG (2019) Effects of pollution, low temperature and influenza syndrome on the excess mortality risk in winter 20162017. BMC Public Health 19(1):1445. https://doi.org/10.1186/ s12889-019-7788-8

Ökten G (2005) Solving linear equations by Monte Carlo simulation. SIAM J Sci Comput 27(2):511-531

Oliveiros B, Caramelo L, Ferreira NC, Caramelo F (2020) Role of temperature and humidity in the modulation of the doubling time of COVID-19 cases. Preprint at https://doi.org/10.1101/2020.03.05. 20031872

Park JE, Son WS, Ryu Y, Choi SB, Kwon O, Ahn I (2020) Effects of temperature, humidity, and diurnal temperature range on influenza incidence in a temperate region. Influenza Other Respir Viruses 14(1):11-18. https://doi.org/10.1111/irv.12682

Pavey TG, Gilson ND, Gomersall SR, Clark B, Trost SG (2017) Field evaluation of a random forest activity classifier for wrist-worn accelerometer data. J Sci Med Sport 20(1):75-80

Peci A, Winter AL, Li Y, Gnaneshan S, Liu J, Mubareka S, Gubbay JB (2019) Effects of absolute humidity, relative humidity, temperature, and wind speed on influenza activity in Toronto, Ontario, Canada. Appl Environ Microbiol 85(6). https://doi.org/10.1128/AEM. 02426-18

Prata DN, Rodrigues W, Bermejo PH (2020) Temperature significantly changes COVID-19 transmission in (sub)tropical cities of Brazil. Sci Total Environ 729:138862. https://doi.org/10.1016/j.scitotenv. 2020.138862

Qi H, Xiao S, Shi R, Ward MP, Chen Y, Tu W, .Zhang Z (2020a) COVID-19 transmission in Mainland China is associated with temperature and humidity: a time-series analysis. Sci Total Environ 728: 138778. https://doi.org/10.1016/j.scitotenv.2020.138778

Qi L, Gao Y, Yang J, Ding XB, Xiong Y, Su K, Liu QY (2020b) The burden of influenza and pneumonia mortality attributable to absolute humidity among elderly people in Chongqing, China, 2012-2018. Sci Total Environ 716:136682. https://doi.org/10.1016/j.scitotenv. 2020.136682

Rahman MS, Islam ARMT (2019) Are precipitation concentration and intensity changing in Bangladesh overtimes? Analysis of the possible causes of changes in precipitation systems, Sci Total Environ 690:370-387. https://doi.org/10.1016/j.scitotenv.2019.06.529
Saha S, Saha M, Mukherjee K, Arabameri A, Thi Ngo PTT, Paul GC (2020) Predicting the deforestation probability using the binary logistic regression, random forest, ensemble rotational forest, REPTree: a case study at the Gumani River Basin, India. Sci Total Environ 730:139197

Sahin M (2020) Impact of weather on COVID-19 pandemic in Turkey. Sci Total Environ 728:138810. https://doi.org/10.1016/j.scitotenv. 2020.138810

Sajadi MM, Habibzadeh P, Vintzileos A, Shokouhi S, Miralles-Wilhelm F, Amoroso A (2020) Temperature and latitude analysis to predict potential spread and seasonality for COVID-19 (Available at SSRN 3550308)

Salam R, Islam ARMT (2020) Potential of RT, bagging and RS ensemble learning algorithms for reference evapotranspiration prediction using climatic data-limited humid region in Bangladesh. J Hydrol 590:125241. https://doi.org/10.1016/j.jhydrol.2020.125241

Salam R, Islam ARMT, Islam S (2019) Spatiotemporal distribution and prediction of groundwater level linked to ENSO teleconnection indices in the northwestern region of Bangladesh. Environ Dev Sustain 22:4509-4535

Shammi M, Bodrud-Doza M, Islam ARMT, Rahman MM (2020a) COVID-19 pandemic, socioeconomic crisis and human stress in resource-limited settings: a case from Bangladesh. Heliyon 6: e04063. https://doi.org/10.1016/j.heliyon.2020.e04063

Shammi M, Bodrud-Doza M, Islam ARMT, Rahman MM (2020b) Strategic assessment of COVID-19 pandemic in Bangladesh: comparative lockdown scenario analysis, public perception, and management for sustainability. Environ Dev Sustain. https://doi.org/10. 1007/s10668-020-00867-y

Shi P, Dong Y, Yan H, Zhao C, Li X, Liu W, Xi S (2020) Impact of temperature on the dynamics of the COVID-19 outbreak in China. Sci Total Environ 728:138890. https://doi.org/10.1016/j.scitotenv. 2020.138890

Snyder RL (2005) Humidity conversion. Davis, University of California: Biometeorology Program

Tellier R (2006) Review of aerosol transmission of influenza A virus. Emerg Infect Dis 12(11):1657-1662. https://doi.org/10.3201/ eid1211.060426

Tobías A, Molina T (2020) Is temperature reducing the transmission of COVID-19? Environ Res 186:109553

Wang M, Jiang A, Gong L, Luo L, Guo W, Li C, Zheng J, Li C, Yang B, Zeng J, Chen Y, Zheng K, Li H (2020) Temperature significant change COVID-19 transmission in 429 cities. medRxiv preprint https://doi.org/10.1101/2020.02.22.20025791

Wu Y, Jing W, Liu J, Ma Q, Yuan J, Wang Y, Liu M (2020) Effects of temperature and humidity on the daily new cases and new deaths of COVID-19 in 166 countries. Sci Total Environ 729:139051. https:// doi.org/10.1016/j.scitotenv.2020.139051

Zhang Y (2013) Likelihood-based and bayesian methods for tweedie compound poisson linear mixed models. Stat Comput 23:743-757

Zhu Y, Xie J (2020) Association between ambient temperature and COVID-19 infection in 122 cities from China. Sci Total Environ 138201. https://doi.org/10.1016/j.scitotenv.2020.138201

Zhu N, Zhang D, Wang W, Li X, Yang B, Song J et al (2020) A novel coronavirus from patients with pneumonia in China, 2019. N Engl J Med 382(8):727-733. https://doi.org/10.1056/NEJMoa2001017

Publisher's note Springer Nature remains neutral with regard to jurisdictional claims in published maps and institutional affiliations. 